\title{
OPEN -308G/A polymorphism of tumor necrosis factor alpha (TNF- $\alpha)$ gene and metabolic syndrome susceptibility: a meta-analysis
}

\author{
Dong Wang ${ }^{1}$, Liqun $\mathrm{He}^{1 \bowtie}$ \& Xiaotian Zhang ${ }^{2 \bowtie}$
}

Many studies tried to assess the relationship between -308G/A polymorphism of tumor necrosis factor alpha (TNF- $\alpha$ ) gene and risk of metabolic syndrome (MS), but their results were contradictory. This meta-analysis aimed to precisely evaluate this association. A systematic literature search was performed in Pubmed database and WanFang Med Online, STATA software 14.0 was used for the meta-analysis. Eleven independent studies containing 3277 cases and 3312 controls were included in our meta-analysis. In overall analysis, significant association was found between -308G/A polymorphism of TNF- $\alpha$ and MS in both allele model (OR 1.47, 95\% CI 1.09-1.98, P 0.013) and dominant model (OR 1.77, 95\% CI 1.21-2.58, $\mathrm{P}$ 0.003). In the subgroup analysis, the $A$ allele was associated with increased risk of MS in Asia group (allele model: OR 1.82 95\% CI 1.31-2.53, P<0.001; dominant model: OR 2.30, 95\% Cl 1.64-3.21 P < 0.001; homozygous model: OR 2.29, 95\% Cl 1.314.01, P 0.004), and decreased risk of MS in Europe group (dominant model: OR $0.83,95 \% \mathrm{Cl} 0.70-0.99$, $\mathrm{P}<0.001$; recessive model: OR $0.51,95 \% \mathrm{Cl} 0.28-0.92$, $\mathrm{P} 0.025$; homozygous model: $\mathrm{OR} 0.4995 \% \mathrm{Cl}$ $0.27-0.89, P$ 0.02). The $A$ allele also appeared to linked to increased risk of MS in CDS group and IDF groups. No significant association was observed in NCEPATPIII group. Our results suggested that -308 G/A of TNF- $\alpha$ gene was a risk factor for MS, but it may played different roles in different ethnics, further studies with larger sample size and more other ethnics should be performed to confirm our conclusions.

Metabolic syndrome (MS) is a multi-component disease characterized by the combination of a series of clinical and biochemical metabolic disorders including insulin resistance, elevated plasma triglyceride levels, decreased HDL-c, hypertension, hyperglycaemia and abdominal obesity. In 1998, the first criteria of MS was made by World Health Organization (WHO) ${ }^{1}$, since then many international organizations and expert groups, such as European Group for the study of Insulin Resistance (EGIR) ${ }^{2}$, the International Diabetes Federation (IDF) ${ }^{3}$, the National Cholesterol Education Program Adult Treatment Panel III (NCEP:ATPIII) ${ }^{4}$, the American Association of Clinical Endocrinology $(\mathrm{AACE})^{5}$, Chinese Diabetes Society ${ }^{6}$, have defined MS using different parameters. Among those definitions, the ones made by NCEP:ATPIII and IDF were the most widely used currently. The morbidity of MS is increasing around the world, which makes MS a huge public health burden for many countries ${ }^{3,7-9}$. Many factors are involved in the development of MS. On one hand, environmental factors such as physical inactivity and improper eating habits are essential determinants for MS. On the other hand, genetic factors also play vital roles in the development of MS.

Tumor necrosis factor alpha $(T N F-\alpha)$ is a multifunctional pro-inflammatory cytokine with both beneficial and destructive functions for human body produced by various kinds of cells such as macrophages, fibroblasts, epithelial cells, adipocyte ${ }^{10}$. As we known, TNF- $\alpha$ could regulate numerous inflammatory and autoimmune processes, and participates in many life activities such as apoptosis, differentiation and cell recruitment ${ }^{11}$. Prior studies also demonstrated that TNF- $\alpha$ combined with other types of pro-inflammatory cytokines contributed to the development of type II diabetes, obesity and obesity-induced insulin resistance, which suggested TNF- $\alpha$ played as an essential role in the development of $\mathrm{MS}^{12-15}$. TNF- $\alpha$ gene is located at $6 \mathrm{p} 21.1-21.3$ chromosomal region, which is near to major histocompatibility complex. Wilson et al. firstly identified a $\mathrm{G}$ to $\mathrm{A}$ variant at

${ }^{1}$ Department of Cardiology, Wuhan No. 1 Hospital, Wuhan Hospital of Traditional Chinese and Western Medicine, 215\# Zhongshan Ave., Wuhan 430022, People's Republic of China. ${ }^{2}$ Hubei Provincial Key Laboratory for Applied Toxicology, Hubei Provincial Center for Disease Control and Prevention, 35\# Zhou Daoquan North Road, Wuhan 430079, People's Republic of China. ${ }^{\circledR}$ email: Liqunhe0902@163.com; xtzhang@mail.bnu.edu.cn 
308 upstream of TNF- $\alpha$ gene promoter region in $1992^{16}$. Subsequent studies has shown that -308G/A had great impact on the transcription activation of TNF- $\alpha$ gene and was relevant with the increased plasma TNF- $\alpha$ plasma levels ${ }^{17}$. Observational studies supported $-308 \mathrm{G} / \mathrm{A}$ of TNF- $\alpha$ gene was associated with the components of MS such as hypertension and insulin resistance ${ }^{18}$. Many studies containing different ethnic subjects tried to reveal the relationship between -308G/A of TNF- $\alpha$ gene and MS susceptibility, however, those results were inconsistent.

In this study, we performed a meta-analysis to assess the accurate impact of the -308G/A polymorphism of $T N F-\alpha$ gene promoter on the MS risk.

\section{Methods}

Literature search. A systemic literature search was performed in Pubmed and Wanfang Online database to identify all the potential studies that involved the association between -308G/A polymorphism of TNF- $\alpha$ gene and MS susceptibility. Following key words were used for our literature search: ("tumor necrosis factor alpha" OR “TNF- $\alpha$ ”) AND (polymorphism OR mutation OR variant) AND (metabolic syndrome OR MetS OR MS). The language was restricted to English and Chinese, and the search process was completed on April 6th 2020.

Inclusion criteria. The following inclusion criteria should be met when the studies were included in this meta-analysis: (1) studies should examine the association between -308G/A polymorphism of TNF- $\alpha$ gene and MS susceptibility; (2) studies should be case-control designed or cohort designed; (3) studies should provide enough data to calculate the odds ratios (ORs) and the corresponding 95\% confidence intervals (CIs).

Data extraction and quality assessment. Two authors independently extracted the following information from each study: the first authors, the years of publication, the demographic information of each study, the numbers of case and control groups, and the frequencies of the three types of genotypes in both cases and controls. Newcastle-Ottawa quality assessment scale was used for the quality assessment of each research ${ }^{19}$.

Statistical analysis. We calculated the pooled ORs and corresponding 95\%CIs to assess the strength of the association between -308G/A polymorphism of TNF- $\alpha$ gene and MS susceptibility. Pooled ORs and 95\% CIs were performed under four genetic models: allele model (A vs.G), dominant model (AA + GA vs. GG), recessive model (AA vs. GG + GA), and homozygous model (AA vs. GG), respectively. We used random effect models to calculate all the pooled ORs and corresponding 95\%CIs. The $\mathrm{Z}$ tests were used to assess the significance of the ORs. Hardy-Weinberg equilibrium (HWE) was tested using Chi-square test in the control groups. Heterogeneity between the studies included in this meta-analysis was evaluated using $\chi^{2}$ based $\mathrm{Q}$ tests and I-square $\left(\mathrm{I}^{2}\right)$ tests. We defined low, moderate, and high degrees of heterogeneity when the values of $\mathrm{I}^{2}$ were $25 \%$, $50 \%$, and $75 \%$, respectively. We carried out sensitive analysis to assess the impact of each study on the pooled ORs and 95\% CIs. The Begg's and Egger's tests were used to evaluate the publication bias. All tests were two-sided, and a value $<0.05$ was considered as statistically significant. STATA software (version 14.0; State Corporation, College Station, TX, USA) was used to perform all the statistical tests in this meta-analysis.

\section{Results}

Study characteristics. Depending on the literature search strategy mentioned above, 658 articles were initially identified in the Pubmed database and Wanfang Med Online. The sift process was shown in Fig. 1. Briefly, 630 articles were excluded after reviewing their titles and abstracts. Of the remaining 28 articles, 17 ones were excluded for the following reasons: six studies were performed for the association between -308G/A polymorphism of TNF- $\alpha$ gene and the components of MS, three studies did not have healthy controls, three studies were for other polymorphism sties of TNF- $\alpha$ gene, two studies were for other disorders, one study with repeating data, one study was meta-analysis, one study with wrong data. Finally, eleven studies containing 3277 cases and 3312 controls were included in our meta-analysis. Eight of the eleven studies were published in English, three ones were in Chinese. The publication time of the eleven studies ranged from 2005 to 2019. There are three types of diagnostic criteria were used for the diagnosis of MS, five studies diagnosed MS using the National Cholesterol Education Program Adult Treatment Panel III (NCEPATP III) definition, four studies adopted International Diabetes Federation (IDF) definition, two studies recruit their subjects using the definition made by Chinese Diabetes Society (CDS). Four different kinds of genotyping methods existed, the numbers of studies used restriction fragment length polymorphism (RFLP) was eight. Golden Gate Assay, Taqman probe, melting curves were respectively used in the remaining three studies. All the studies included in our studies were in $\operatorname{HWE}(\mathrm{P}>0.05)$. The general characteristics of the eleven studies and the frequencies of different genotypes extracted from each study were shown in the Table 1.

Meta-analysis. We evaluated the association between -308G/A polymorphism of TNF- $\alpha$ gene and MS susceptibility in four genetic models. Overall, significant association was found in both allele model (OR 1.47, 95\% CI 1.09-1.98, P 0.013) (Fig. 2) and dominant model (OR 1.77, 95\% CI 1.21-2.58, P 0.003). No significant association was observed in recessive model (OR 1.08, 95\% CI 0.67-1.74, P 0.744) and homozygous model (OR $1.50,95 \%$ CI 0.84-2.70, P 0.174).

In the subgroup analysis performed by the regions of the studies, A allele showed increased risk of MS in Asia group (allele model: OR 1.82 95\% CI 1.31-2.53, P<0.001; dominant model: OR 2.30, 95\% CI 1.64-3.21 P<0.001; homozygous model: OR 2.29, 95\% CI 1.31-4.01, P 0.004). Inversely, the A allele showed decreased risk of MS in Europe group (dominant model: OR 0.83, 95\% CI 0.70-0.99, $\mathrm{P}<0.001$; recessive model: OR $0.51,95 \% \mathrm{CI}$ 0.28-0.92, P 0.025; homozygous model: OR 0.49 95\% CI 0.27-0.89, P 0.02) (Fig. 3). When subgroup analysis was 


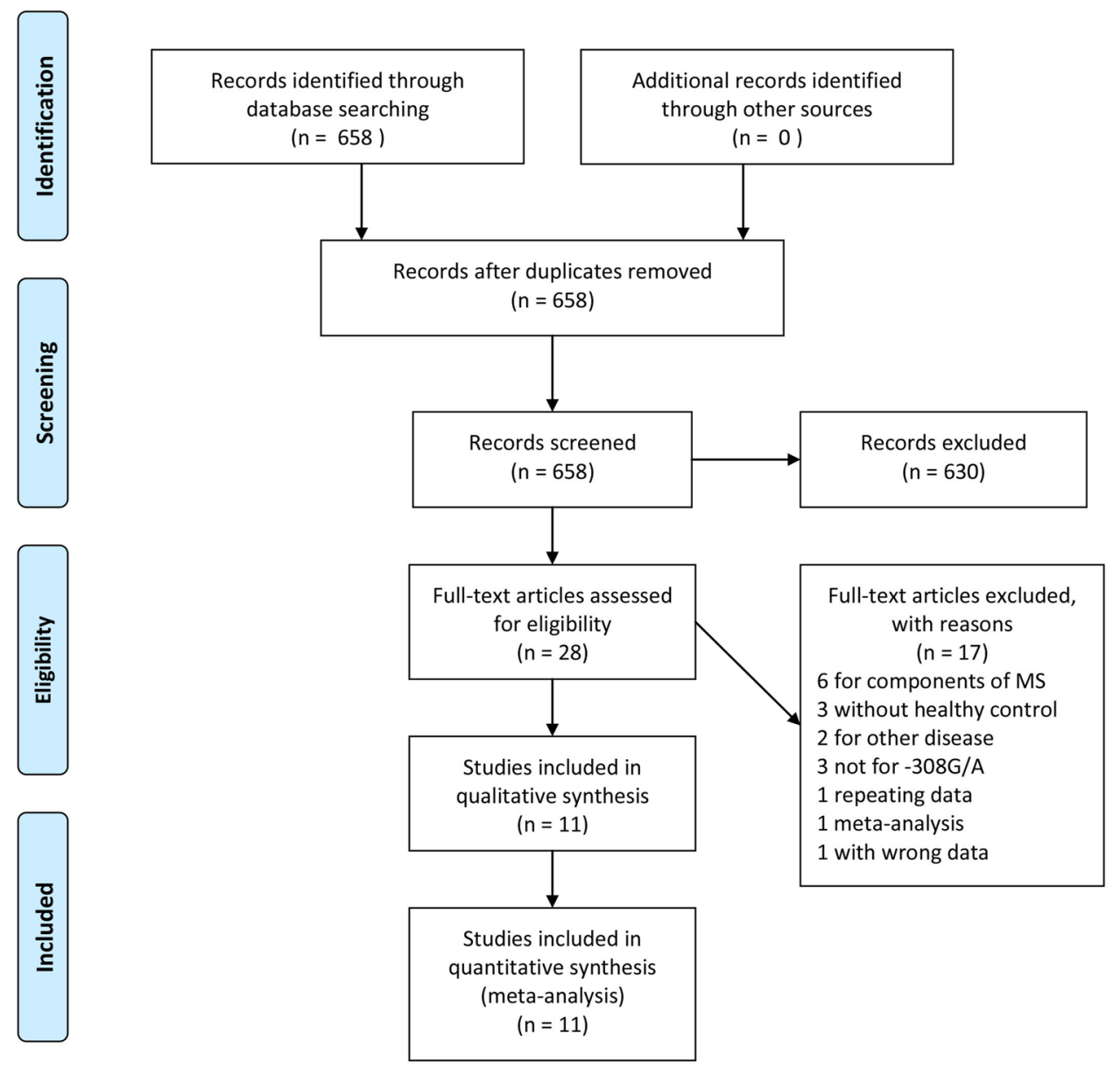

Figure 1. Flow chart of research and selection process.

\begin{tabular}{|c|c|c|c|c|c|c|c|c|c|c|c|c|c|c|c|c|c|c|c|c|}
\hline \multirow[b]{3}{*}{ Author } & \multirow[b]{3}{*}{ Year } & \multirow[b]{3}{*}{ Language } & \multirow[b]{3}{*}{ Country } & \multirow{3}{*}{$\begin{array}{l}\text { Diagnostic } \\
\text { criteria }\end{array}$} & \multirow{3}{*}{$\begin{array}{l}\text { Source } \\
\text { of } \\
\text { control }\end{array}$} & \multirow{3}{*}{$\begin{array}{l}\text { Sample } \\
\text { size } \\
\text { (case/ } \\
\text { control) }\end{array}$} & \multirow[b]{3}{*}{ Method } & \multicolumn{10}{|c|}{ Genotype } & \multirow{3}{*}{ HWE } & \multirow{3}{*}{ Nos } & \multirow{3}{*}{ Ref } \\
\hline & & & & & & & & \multicolumn{5}{|l|}{ Case } & \multicolumn{5}{|c|}{ Control } & & & \\
\hline & & & & & & & & G & A & GG & GA & AA & G & $\mathbf{A}$ & GG & GA & AA & & & \\
\hline $\mathrm{Bu}$ & 2014 & English & China & IDF & $\mathrm{HB}$ & $200 / 200$ & RFLP & 351 & 49 & 162 & 27 & 11 & 384 & 16 & 188 & 8 & 4 & Yes & 7 & 20 \\
\hline Uzma & 2019 & English & Pakistan & IDF & HB & $224 / 200$ & RFLP & 301 & 147 & 100 & 101 & 23 & 280 & 120 & 102 & 76 & 22 & Yes & 8 & 21 \\
\hline Vani & 2012 & English & India & \begin{tabular}{|l|} 
NCEPATP \\
III
\end{tabular} & $\mathrm{HB}$ & $269 / 272$ & RFLP & 429 & 109 & 169 & 91 & 9 & 502 & 42 & 230 & 42 & 0 & Yes & 6 & 22 \\
\hline Zhao & 2013 & Chinese & China & \begin{tabular}{|l|} 
NCEPATP \\
III
\end{tabular} & $\mathrm{HB}$ & $600 / 600$ & Taqman & 1083 & 117 & 488 & 107 & 5 & 1142 & 58 & 543 & 56 & 1 & Yes & 7 & 23 \\
\hline $\begin{array}{l}\text { Cath- } \\
\text { erine }\end{array}$ & 2010 & English & France & $\begin{array}{l}\text { NCEPATP } \\
\text { III }\end{array}$ & PB & $877 / 877$ & $\begin{array}{l}\text { Golden } \\
\text { Gate } \\
\text { Assay }\end{array}$ & 1549 & 205 & 683 & 183 & 11 & 1494 & 260 & 635 & 224 & 18 & Yes & 6 & 24 \\
\hline Ranbir & 2012 & English & India & \begin{tabular}{|l|} 
NCEPATP \\
III
\end{tabular} & HB & $245 / 321$ & RFLP & 236 & 254 & 11 & 214 & 20 & 343 & 299 & 56 & 231 & 34 & Yes & 8 & 25 \\
\hline Aline & 2005 & English & France & $\begin{array}{l}\text { NCEPATP } \\
\text { III }\end{array}$ & $\mathrm{PB}$ & $601 / 594$ & RFLP & 496 & 79 & 198 & 73 & 3 & 1409 & 269 & 599 & 211 & 29 & Yes & 7 & 26 \\
\hline Gong & 2016 & Chinese & China & CDS & HB & $119 / 60$ & RFLP & 204 & 34 & 89 & 26 & 4 & 111 & 9 & 51 & 9 & 0 & Yes & 7 & 27 \\
\hline Fan & 2019 & Chinese & China & CDS & HB & $48 / 60$ & RFLP & 81 & 15 & 35 & 11 & 2 & 113 & 7 & 53 & 7 & 0 & Yes & 8 & 28 \\
\hline Seyed & 2015 & English & Iran & IDF & HB & $94 / 128$ & RFLP & 122 & 66 & 41 & 40 & 20 & 168 & 88 & 60 & 48 & 20 & Yes & 7 & 29 \\
\hline Szkup & 2018 & English & Poland & IDF & $\mathrm{PB}$ & $118 / 298$ & $\begin{array}{l}\text { Melting } \\
\text { curves }\end{array}$ & 201 & 35 & 85 & 31 & 2 & 515 & 81 & 226 & 63 & 9 & Yes & 8 & 30 \\
\hline
\end{tabular}

Table 1. General characteristics of studies included in the meta-analysis. $H B$ hospital based, $P B$ population based, IDF the International Diabetes Federation, NCEPATP III the National Cholesterol Education Program Adult Treatment Panel III, HWE Hardy-Weinberg Equilibrium, CDS Chinese Diabetes Society, RFLP restriction fragment length polymorphism, NOS Newcastle-Ottawa Score. 


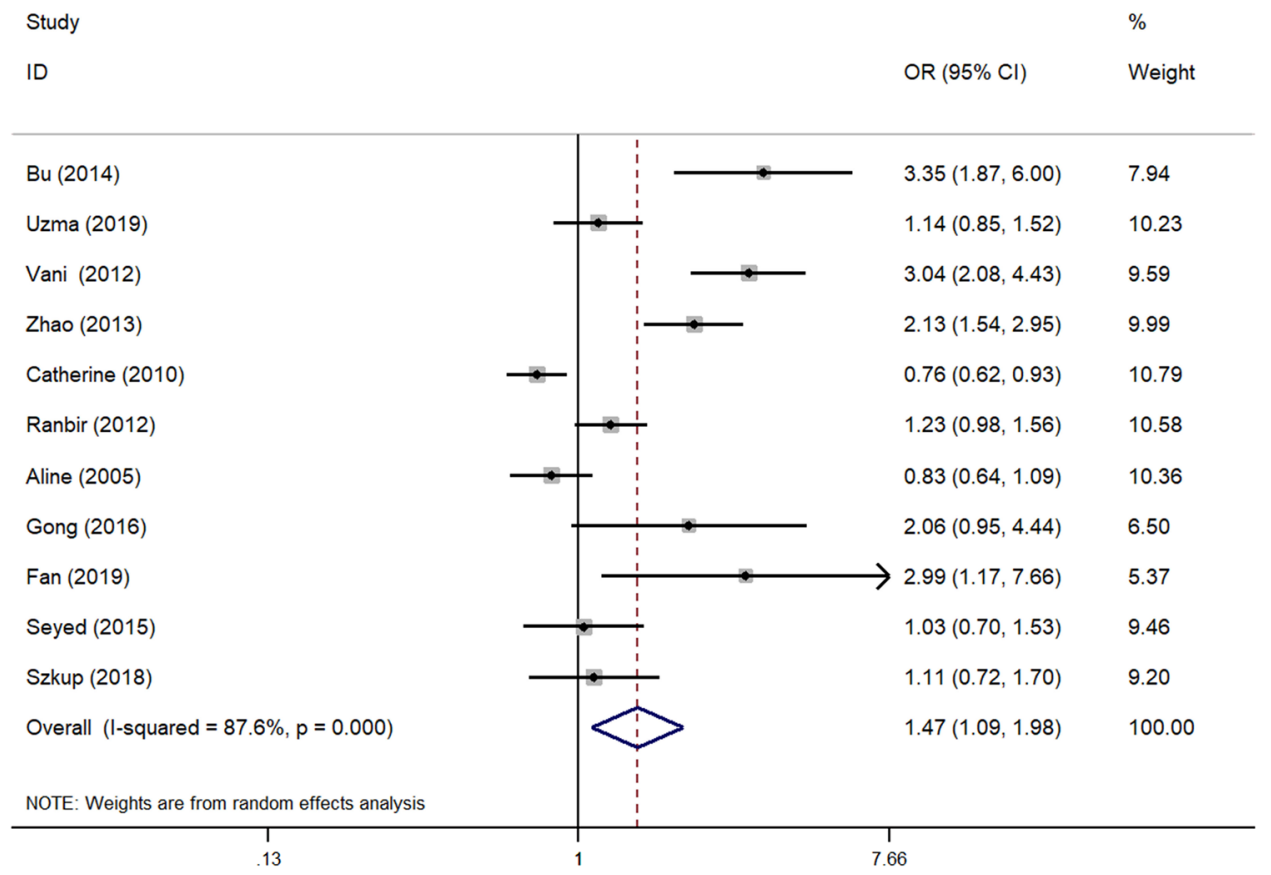

Figure 2. Forest plot of the association between -308G/A polymorphism of TNF- $\alpha$ gene promoter and MS risk under allele model. OR odds ratio, CI confidence interval.

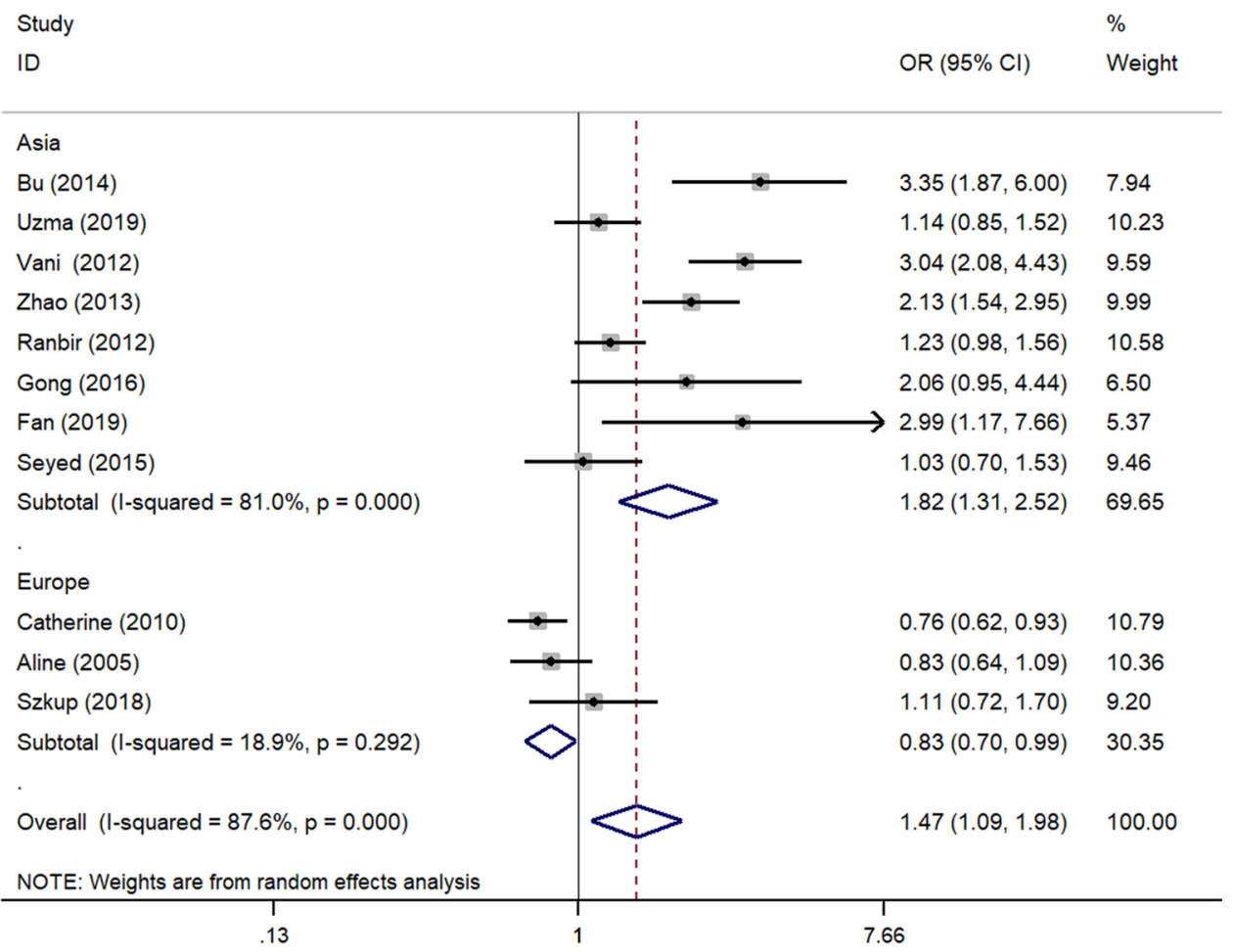

Figure 3. Subgroup analysis stratified by regions under allele model. OR odds ratio, CI confidence interval.

stratified by diagnostic criteria, the A allele showed increased risk of MS in CDS group (allele model: OR 2.39, 95\% CI 1.31-4.34, P 0.004; dominant model: OR 2.23, 95\% CI 1.18-4.21, P 0.014) and IDF groups (dominant model: OR 1.56, 95\% CI 1.03-2.36, P 0.038) (Fig. 4). No significant association was observed in NCEP ATP III group. When stratified by the source of control, the results were the same as the ones stratified by regions of the studies (Fig. 4; Table 2). 


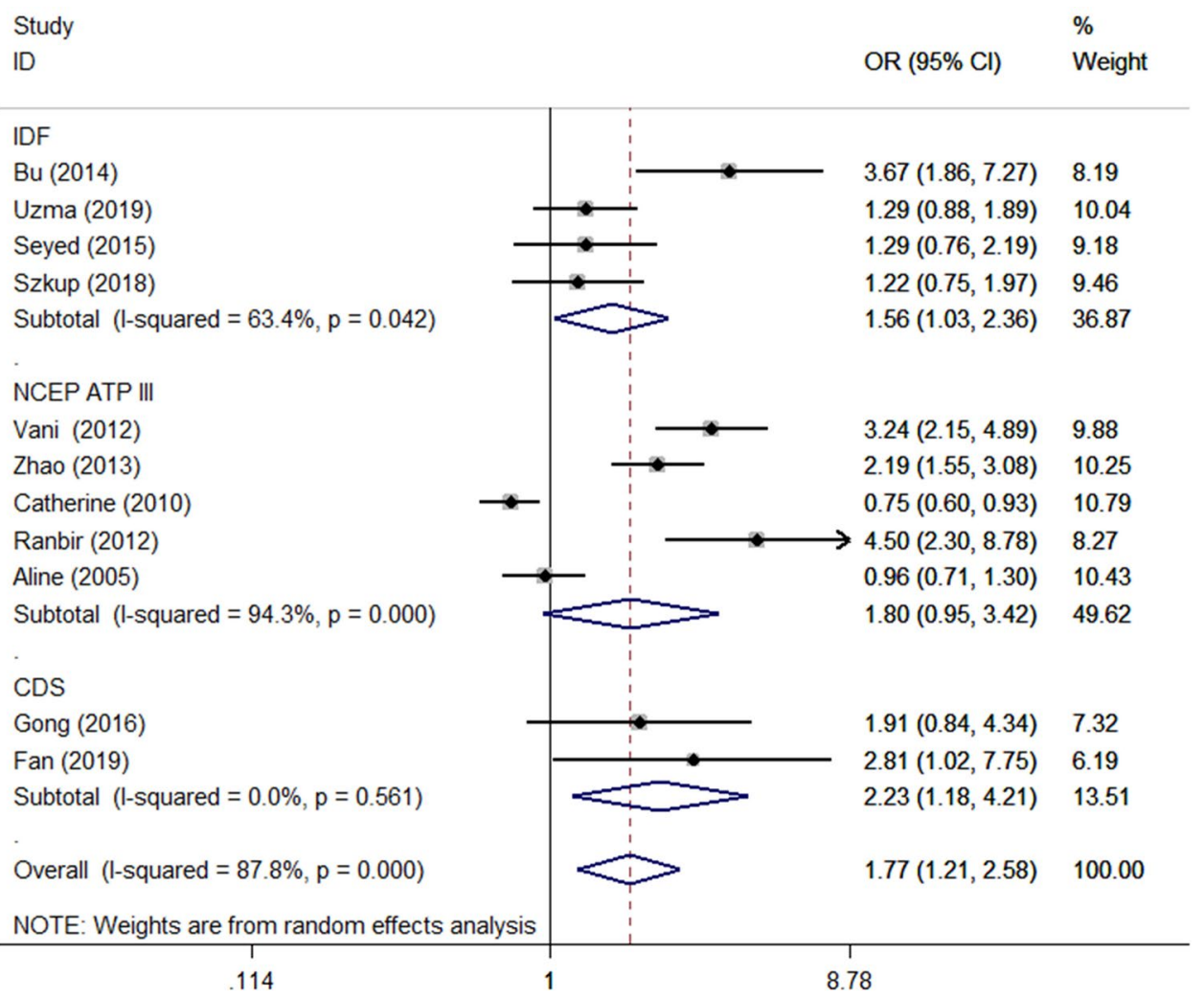

Figure 4. Subgroup analysis stratified by criteria under dominant model. OR odds ratio, CI confidence interval. IDF the International Diabetes Federation, NCEPATP III the National Cholesterol Education Program Adult Treatment Panel III; CDS Chinese Diabetes Society.

Results of tests for heterogeneity were also shown in Table 2. High degree heterogeneity was shown in allele model $\left(\mathrm{I}^{2} 80.93 \%, \mathrm{P}_{\mathrm{h}}<0.001\right)$ and dominant model $\left(\mathrm{I}^{2} 82.19 \%, \mathrm{P}_{\mathrm{h}}<0.001\right)$. Low and moderate degree heterogeneity was found in recessive model $\left(\mathrm{I}^{2} 49.94 \%, \mathrm{P}_{\mathrm{h}} 0.032\right)$ homozygous model $\left(\mathrm{I}^{2} 61.00 \%, \mathrm{P}_{\mathrm{h}} 0.004\right)$, respectively. Sensitive analysis was performed by omitting one study at a time and then the ORs and $95 \% \mathrm{CI}$ of the remaining studies were recalculated. In this study, the pooled ORs and the $95 \%$ CI calculated after excluding single study did not show violent fluctuation compared with the value of overall analysis, suggesting the results of our study were stable. Publication bias analysis was performed using Begg's and Egger's tests in all the four genetic models. As shown in Table 2, all the $\mathrm{P}$ values were $>0.05$ except the Egger's test in dominant model $(\mathrm{P}=0.017)$.

\section{Discussion}

Prior studies have revealed chronic inflammation may be one of most important promoting factors for the development of $\mathrm{MS}^{31-35}$. TNF- $\alpha$ secreted by M1 pro-inflammatory adipose tissue macrophages is one of the most important pro-inflammatory mediators in various organs of human body and could initiate the NF- $\kappa \mathrm{B}$ and JNK pathways involved in the insulin resistance and the apoptosis of the $\beta$ cells within the pancreatic islets ${ }^{36-41}$, which suggested TNF- $\alpha$ may play a central role in the development of MS. Many case-control studies tried to assess the relationship between -308G/A polymorphism of TNF- $\alpha$ gene promoter and the risk of MS, however, their results were inconsistent and with low statistic power due to the small sample sizes of those studies.

In this study, we performed a meta-analysis to evaluate the relationship between -308G/A polymorphism of $T N F-\alpha$ gene promoter and MS risk. Eleven studies containing 3277 cases and 3312 controls were included totally. Our results revealed that the A allele increased 48\%, 77\% risk for MS in allele model and dominant model in overall study, respectively. In the subgroup analysis, it was of great interests for us to find opposite conclusions in the Asia and Europe subgroup. The A allele distinctly increased MS susceptibilities in allele model (OR 1.82, 95\% CI 1.31-2.53, P <0.001), dominant model (OR 2.30, 95\% CI 1.64-3.21, P<0.001), and homozygous model (OR 2.29, 95\% CI 1.31-4.01, P 0.004) in Asia subgroups, while in Europe subgroup the A allele seemed to play a protective role for MS in allele model (OR 0.83, 95\% CI 0.70-0.99, P 0.033), recessive model(OR 0.51, 95\% CI $0.28-0.92, \mathrm{P} 0.025$ ) and homozygous model (OR 0.49, 95\% CI 0.27-0.89, P 0.02). Our results showed the complexities for MS once again. Why did the same variant play antipodal roles of MS in different countries? MS is a kind of complex and polygenetic disorder. Different ethnic group may have entirely different genetic background. Silvia et al. performed a meta-analysis to assess the relationship between -308G/A polymorphism and the risk of MS components ${ }^{18}$. They found ethnicity was also an important factor to influence relationship between -308G/A polymorphism and hypertension, T2DM and obesity. Our study further demonstrated that -308G/A polymorphism could play different roles in the development of MS in different ethnicities on the base 


\begin{tabular}{|c|c|c|c|c|c|c|c|c|c|c|}
\hline Group & No. of studies & Case & Control & Pool OR & $95 \% \mathrm{CI}$ & $\mathbf{P}$ & $I^{2}$ & $\mathbf{P}_{\mathrm{h}}$ & Begg' test & $\begin{array}{l}\text { Egger' } \\
\text { test }\end{array}$ \\
\hline \multicolumn{11}{|c|}{ Allele model (A vs. G) } \\
\hline Overall & 11 & 3277 & 3312 & 1.47 & $1.09-1.98$ & 0.013 & $80.93 \%$ & $<0.001$ & 0.061 & 0.032 \\
\hline \multicolumn{11}{|l|}{ Region } \\
\hline Asia & 8 & 1799 & 1841 & 1.82 & $1.31-2.53$ & $<0.001$ & $81.00 \%$ & $<0.001$ & & \\
\hline Europe & 3 & 1696 & 1796 & 0.83 & $0.70-0.99$ & 0.033 & $18.90 \%$ & 0.0048 & & \\
\hline \multicolumn{11}{|c|}{ Diagnostic criteria } \\
\hline IDF & 4 & 636 & 826 & 1.37 & $0.90-2.01$ & 0.138 & $76.30 \%$ & 0.006 & & \\
\hline NCEP ATP III & 5 & 2592 & 2664 & 1.36 & $0.85-2.18$ & 0.2 & $93.50 \%$ & $<0.001$ & & \\
\hline CDS & 2 & 167 & 120 & 2.39 & $1.31-4.34$ & 0.004 & $0.00 \%$ & 0.546 & & \\
\hline \multicolumn{11}{|c|}{ Dominant model (AA + GA vs GG) } \\
\hline Overall & 11 & 3277 & 3312 & 1.77 & $1.21-2.58$ & 0.003 & $82.19 \%$ & $<0.001$ & 0.161 & 0.017 \\
\hline \multicolumn{11}{|l|}{ Region } \\
\hline Asia & 8 & 1799 & 1841 & 2.3 & $1.64-3.21$ & $<0.001$ & $67.70 \%$ & 0.003 & & \\
\hline Europe & 3 & 1696 & 1796 & 0.9 & $0.69-1.17$ & 0.426 & $51.80 \%$ & 0.126 & & \\
\hline \multicolumn{11}{|c|}{ Diagnostic criteria } \\
\hline IDF & 4 & 636 & 826 & 1.56 & $1.03-2.36$ & 0.038 & $63.40 \%$ & 0.042 & & \\
\hline NCEP ATP III & 5 & 2592 & 2664 & 1.8 & $0.95-3.42$ & 0.72 & $94.30 \%$ & $<0.001$ & & \\
\hline CDS & 2 & 167 & 120 & 2.23 & $1.18-4.21$ & 0.014 & $0.00 \%$ & 0.561 & & \\
\hline \multicolumn{11}{|c|}{ Recessive model (AA vs GG + GA) } \\
\hline Overall & 11 & 3277 & 3312 & 1.08 & $0.67-1.74$ & 0.744 & $49.40 \%$ & 0.032 & 0.161 & 0.077 \\
\hline \multicolumn{11}{|l|}{ Region } \\
\hline Asia & 8 & 1799 & 1841 & 1.52 & $0.87-2.67$ & 0.14 & $47.30 \%$ & 0.066 & & \\
\hline Europe & 3 & 1696 & 1796 & 0.51 & $0.28-0.92$ & 0.025 & $0.00 \%$ & 0.636 & & \\
\hline \multicolumn{11}{|c|}{ Diagnostic criteria } \\
\hline IDF & 4 & 636 & 826 & 1.19 & $0.73-1.95$ & 0.48 & $22.10 \%$ & 0.278 & & \\
\hline NCEP ATP III & 5 & 2592 & 2664 & 0.91 & $0.39-2.11$ & 0.821 & $63.10 \%$ & 0.028 & & \\
\hline CDS & 2 & 167 & 120 & 5.5 & $0.66-45.81$ & 0.115 & $0.00 \%$ & 0.028 & & \\
\hline \multicolumn{11}{|c|}{ Homozygous model (AA vs GG) } \\
\hline Overall & 11 & 3277 & 3312 & 1.5 & $0.84-2.70$ & 0.174 & $61.00 \%$ & 0.004 & 0.533 & 0.169 \\
\hline \multicolumn{11}{|l|}{ Region } \\
\hline Asia & 8 & 1799 & 1841 & 2.29 & $1.31-4.01$ & 0.004 & $37.20 \%$ & 0.132 & & \\
\hline Europe & 3 & 1696 & 1796 & 0.49 & $0.27-0.89$ & 0.02 & $0.00 \%$ & 0.686 & & \\
\hline \multicolumn{11}{|c|}{ Diagnostic criteria } \\
\hline IDF & 4 & 636 & 826 & 1.34 & $0.81-2.21$ & 0.256 & $19.70 \%$ & 0.291 & & \\
\hline NCEP ATP III & 5 & 2592 & 2664 & 1.65 & $0.48-5.75$ & 0.428 & $79.50 \%$ & 0.001 & & \\
\hline CDS & 2 & 167 & 120 & 6.2 & $0.74-51.78$ & 0.092 & $0.00 \%$ & 0.862 & & \\
\hline
\end{tabular}

Table 2. The association between -308G/A polymorphism of TNF- $\alpha$ gene and MS susceptibility. IDF the International Diabetes Federation, NCEPATP III the National Cholesterol Education Program Adult Treatment Panel III, CDS Chinese Diabetes Society, OR odds ratio, CI confidence interval.

of Silvia et al. Some issues should be discussed when we explained this result: firstly, the three studies for Europe included were population-based, while the eight studies from Asia were hospital-based, whether the different methods to include the control populations by each study influence the results of the two subgroups still need to be consulted, even if the minor allele frequencies of A was near to each other between the two the control groups (0.173 in Asia group and 0.151 in Europe group). Secondly, as another risk factor, age also played vital roles in the development of MS, another meta-analysis performed by us revealed the rs 9939609 of FTO gene was associated with MS in Chinese adults but not in Chinese children and adolescents ${ }^{42}$, that means time is needed in the interaction between genetic factors and environment. The subgroup analysis stratified in different age groups could not be performed in our study. Thirdly, in our study, only three studies in Europe were included the sample size was still limited, further studies with larger sample sizes especially from Europe should perform to confirm our conclusions.

The heterogeneity of meta-analysis usually comes from three aspects: clinical heterogeneity, statistical heterogeneity, and methodological heterogeneity. During the overall analysis, high degrees of heterogeneity was found in the allele model $\left(\mathrm{I}^{2}=80.93 \%, \mathrm{P}<0.001\right)$ and dominant model $\left(\mathrm{I}^{2}=82.19 \%, \mathrm{P}<0.001\right)$, while the heterogeneity in recessive model and homozygous model was low $\left(\mathrm{I}^{2}=49.40 \%, \mathrm{P} 0.032\right)$ and moderate $\left(\mathrm{I}^{2}=61.00 \%, \mathrm{P} 0.004\right)$. The results from overall analysis indicated that the different statistical methods could be a source of heterogeneity. In the subgroup analysis, we found the levels of heterogeneity were dramatically decreased in the Asia and Europe subgroups in all the four genetic models, suggesting that the ethnic may be an important source of heterogeneity. 
In the subgroup analysis stratified by the diagnostic criteria, lower levels of heterogeneity were found in IDF subgroups and no heterogeneity was found in CDS subgroup, the main heterogeneity came from the NCEP ATP III subgroups, which means diagnostic criteria should be another important source of heterogeneity.

Begg's and Egger's tests were performed to assess the publication bias tests, A P value 0.017 was found in the Egger's test in dominant model. Although there were no statistical significance was found in the other Begg's and Egger's tests, potential publication bias may exist in our study. Because only eleven studies were included in our meta-analysis, limited number of studies may also contributed to the results of the tests for publication bias.

Our study still had several limitations should be mentioned: firstly, because we searched the articles only in Chinese and English, researches published in other languages were ignored, that may result in bias; secondly, other risk factors of MS such as physical inactivity, excessive food intake were not be considered in our metaanalysis; thirdly, the total sample size still limited in our research, and only studies from Asia and Europe were included, further studies with larger sample size and more other ethnics should be performed to confirm our conclusions.

To our knowledge, this is the first meta-analysis to assess the relationship between the -308G/A polymorphism of TNF- $\alpha$ gene promoter and the susceptibility of the MS. Our results suggested -308G/A polymorphism was significantly associated with increased MS susceptibility in overall analysis, in the further analysis a completely apposite result was found in the Asia and Europe subgroup. Our results illuminated the complex impact of $-308 \mathrm{G} / \mathrm{A}$ polymorphism of TNF- $\alpha$ gene promoter played on the MS susceptibility.

Received: 12 May 2020; Accepted: 18 January 2021

Published online: 15 February 2021

\section{References}

1. Alberti, K. G. \& Zimmet, P. Z. Definition, diagnosis and classification of diabetes mellitus and its complications. Part 1: Diagnosis and classification of diabetes mellitus provisional report of a WHO consultation. Diab. Med. J. Brit. Diab. Assoc. 15, 539-553. https ://doi.org/10.1002/(SICI)1096-9136(199807)15:7\%3c539::AID-DIA668\%3e3.0.CO;2-S (1998).

2. Balkau, B. \& Charles, M. A. Comment on the provisional report from the WHO consultation. European Group for the Study of Insulin Resistance (EGIR). Diab. Med. J. Brit. Diab. Assoc. 16, 442-443. https://doi.org/10.1046/j.1464-5491.1999.00059.x (1999).

3. Alberti, K. G., Zimmet, P., Shaw, J. \& Grxoup, I. D. F. E. T. F. C. The metabolic syndrome-a new worldwide definition. Lancet 366, 1059-1062. https://doi.org/10.1016/S0140-6736(05)67402-8 (2005).

4. Expert Panel on Detection, E. \& Treatment of High Blood Cholesterol in, A. Executive summary of the third report of the national cholesterol education program (NCEP) expert panel on detection, evaluation, and treatment of high blood cholesterol in adults (Adult Treatment Panel III). JAMA 285, 2486-2497. https://doi.org/10.1001/jama.285.19.2486 (2001).

5. Einhorn, D. et al. American College of Endocrinology position statement on the insulin resistance syndrome. Endocrine Pract. 9 , 237-252 (2003).

6. Cooperative group of metabolic syndrome research, D. B., Chinese Medical Association. Recommendations of the Chinese Diabetes Society on metabolic syndrome. Chin. J. Diabetes Mellitus 12, 156-161 (2004).

7. Ekelund, U. et al. Prevalence and correlates of the metabolic syndrome in a population-based sample of European youth. Am. J. Clin. Nutr. 89, 90-96. https://doi.org/10.3945/ajcn.2008.26649 (2009).

8. Steinberger, J. et al. Progress and challenges in metabolic syndrome in children and adolescents: A scientific statement from the American Heart Association Atherosclerosis, Hypertension, and Obesity in the Young Committee of the Council on Cardiovascular Disease in the Young; Council on Cardiovascular Nursing; and Council on Nutrition, Physical Activity, and Metabolism. Circulation 119, 628-647. https://doi.org/10.1161/CIRCULATIONAHA.108.191394 (2009).

9. Grundy, S. M. Metabolic syndrome pandemic. Arterioscler. Thromb. Vasc. Biol. 28, 629-636. https://doi.org/10.1161/ATVBA HA.107.151092 (2008).

10. Koh, K. K., Han, S. H. \& Quon, M. J. Inflammatory markers and the metabolic syndrome: Insights from therapeutic interventions. J. Am. Coll. Cardiol. 46, 1978-1985. https://doi.org/10.1016/j.jacc.2005.06.082 (2005).

11. Ehlers, S. Role of tumour necrosis factor (TNF) in host defence against tuberculosis: Implications for immunotherapies targeting TNF. Ann. Rheum. Dis. 62(Suppl 2), 37-42. https://doi.org/10.1136/ard.62.suppl_2.ii37 (2003).

12. Hamada, D. et al. Suppressive effects of insulin on tumor necrosis factor-dependent early osteoarthritic changes associated with obesity and type 2 diabetes mellitus. Arthritis Rheumatol. 68, 1392-1402. https://doi.org/10.1002/art.39561 (2016).

13. da Rocha, A. F. et al. Tumor necrosis factor alpha abolished the suppressive effect of insulin on hepatic glucose production and glycogenolysis stimulated by cAMP. Pharmacol. Rep. 66, 380-385. https://doi.org/10.1016/j.pharep.2013.12.005 (2014).

14. Kabayama, K. et al. TNFalpha-induced insulin resistance in adipocytes as a membrane microdomain disorder: Involvement of ganglioside GM3. Glycobiology 15, 21-29. https://doi.org/10.1093/glycob/cwh135 (2005).

15. Ritchie, S. A. \& Connell, J. M. The link between abdominal obesity, metabolic syndrome and cardiovascular disease. Nutr. Metab. Cardiovasc. Dis. 17, 319-326. https://doi.org/10.1016/j.numecd.2006.07.005 (2007).

16. Wilson, A. G., di Giovine, F. S., Blakemore, A. I. \& Duff, G. W. Single base polymorphism in the human tumour necrosis factor alpha (TNF alpha) gene detectable by NcoI restriction of PCR product. Hum. Mol. Genet. 1, 353. https://doi.org/10.1093/hmg/1.5.353 (1992).

17. Abraham, L. J. \& Kroeger, K. M. Impact of the -308 TNF promoter polymorphism on the transcriptional regulation of the TNF gene: Relevance to disease. J. Leukoc. Biol. 66, 562-566. https://doi.org/10.1002/jlb.66.4.562 (1999).

18. Sookoian, S. C., Gonzalez, C. \& Pirola, C. J. Meta-analysis on the G-308A tumor necrosis factor alpha gene variant and phenotypes associated with the metabolic syndrome. Obes. Res. 13, 2122-2131. https://doi.org/10.1038/oby.2005.263 (2005).

19. Stang, A. Critical evaluation of the Newcastle-Ottawa scale for the assessment of the quality of nonrandomized studies in metaanalyses. Eur. J. Epidemiol. 25, 603-605. https://doi.org/10.1007/s10654-010-9491-z (2010).

20. Bu, D. Y. et al. Association of polymorphisms in stress-related TNFalpha and NPY genes with the metabolic syndrome in Han and Hui ethnic groups. Asian Pac. J. Cancer Prev. 15, 5895-5900. https://doi.org/10.7314/apjcp.2014.15.14.5895 (2014).

21. Zafar, U., Khaliq, S., Ahmad, H. U. \& Lone, K. P. Serum profile of cytokines and their genetic variants in metabolic syndrome and healthy subjects: A comparative study. Biosci. Rep. https://doi.org/10.1042/BSR20181202 (2019).

22. Gupta, V. et al. Association of TNF-alpha promoter gene G-308A polymorphism with metabolic syndrome, insulin resistance, serum TNF-alpha and leptin levels in Indian adult women. Cytokine 57, 32-36. https://doi.org/10.1016/j.cyto.2011.04.012 (2012).

23. Zhao, C. Association of Hsp70-1 Gene $-110,+190$ and TNF- $a$ Gene -308 Polymorphisms with Metabolic Syndrome. Master's Thesis of Ningxia Medical University (2013). 
24. Phillips, C. M. et al. Additive effect of polymorphisms in the IL-6, LTA, and TNF-\{alpha\} genes and plasma fatty acid level modulate risk for the metabolic syndrome and its components. J. Clin. Endocrinol. Metab. 95, 1386-1394. https://doi.org/10.1210/jc.20091081 (2010).

25. Sobti, R. C., Kler, R., Sharma, Y. P., Talwar, K. K. \& Singh, N. Risk of obesity and type 2 diabetes with tumor necrosis factor-alpha 308G/A gene polymorphism in metabolic syndrome and coronary artery disease subjects. Mol. Cell. Biochem. 360, 1-7. https:// doi.org/10.1007/s11010-011-0917-z (2012).

26. Meirhaeghe, A., Cottel, D., Amouyel, P. \& Dallongeville, J. Lack of association between certain candidate gene polymorphisms and the metabolic syndrome. Mol. Genet. Metab. 86, 293-299. https://doi.org/10.1016/j.ymgme.2005.05.006 (2005).

27. Gong, X., Ma, Q. \& Sun, Z. Correlation analysis of TNFa mRNA expression gene polymorphism in patients with metabolic syndrome and asthma. Guizhou Med. J. 40, 25-27 (2016).

28. Jia, S., Zhang, W., Ji, X., Li, J. \& Wang, H. Association of TNF-alpha gene G-308A polymorphism and mRNA expression with metabolic syndrome in asthmatic patients. Chin. J. Immunol. 29, 960-968. https://doi.org/10.3969/j.issn.1000-484X.2013.09.016 (2013).

29. Mirhafez, S. R. et al. Association of tumor necrosis factor-alpha promoter G-308A gene polymorphism with increased triglyceride level of subjects with metabolic syndrome. Gene 568, 81-84. https://doi.org/10.1016/j.gene.2015.05.019 (2015).

30. Szkup, M., Chelmecka, E., Lubkowska, A., Owczarek, A. J. \& Grochans, E. The influence of the TNFalpha rs 1800629 polymorphism on some inflammatory biomarkers in 45-60-year-old women with metabolic syndrome. Aging 10, 2935-2943. https://doi. org/10.18632/aging.101600 (2018).

31. Arkan, M. C. et al. IKK-beta links inflammation to obesity-induced insulin resistance. Nat. Med. 11, 191-198. https://doi. org/10.1038/nm1185 (2005).

32. Hirosumi, J. et al. A central role for JNK in obesity and insulin resistance. Nature 420, 333-336. https://doi.org/10.1038/natur $\mathrm{e} 01137$ (2002).

33. Nakamura, T. et al. Double-stranded RNA-dependent protein kinase links pathogen sensing with stress and metabolic homeostasis. Cell 140, 338-348. https://doi.org/10.1016/j.cell.2010.01.001 (2010).

34. Hotamisligil, G. S. Endoplasmic reticulum stress and the inflammatory basis of metabolic disease. Cell 140, 900-917. https://doi. org/10.1016/j.cell.2010.02.034 (2010).

35. Vandanmagsar, B. et al. The NLRP3 inflammasome instigates obesity-induced inflammation and insulin resistance. Nat. Med. 17, 179-188. https://doi.org/10.1038/nm.2279 (2011).

36. Olson, A. L. Regulation of GLUT4 and insulin-dependent glucose flux. ISRN Mol. Biol. 2012, 856987. https://doi. org/10.5402/2012/856987 (2012).

37. Huang, S. \& Czech, M. P. The GLUT4 glucose transporter. Cell Metab. 5, 237-252. https://doi.org/10.1016/j.cmet.2007.03.006 (2007).

38. Guilherme, A., Virbasius, J. V., Puri, V. \& Czech, M. P. Adipocyte dysfunctions linking obesity to insulin resistance and type 2 diabetes. Nat. Rev. Mol. Cell Biol. 9, 367-377. https://doi.org/10.1038/nrm2391 (2008).

39. Fasshauer, M. \& Paschke, R. Regulation of adipocytokines and insulin resistance. Diabetologia 46, 1594-1603. https://doi. org/10.1007/s00125-003-1228-z (2003).

40. Akash, M. S., Rehman, K. \& Chen, S. Role of inflammatory mechanisms in pathogenesis of type 2 diabetes mellitus. J. Cell. Biochem. 114, 525-531. https://doi.org/10.1002/jcb.24402 (2013).

41. Akash, M. S., Shen, Q., Rehman, K. \& Chen, S. Interleukin-1 receptor antagonist: A new therapy for type 2 diabetes mellitus. J. Pharm. Sci. 101, 1647-1658. https://doi.org/10.1002/jps.23057 (2012).

42. Wang, D., Wu, Z., Zhou, J. \& Zhang, X. Rs 9939609 polymorphism of the fat mass and obesity-associated (FTO) gene and metabolic syndrome susceptibility in the Chinese population: A meta-analysis. Endocrine https://doi.org/10.1007/s12020-020-02280-x (2020).

\section{Acknowledgements}

This work was supported by Grants from the Natural Science Foundation of Hubei Province (no. 2019CFB405), Hubei Provincial Health and Family Planning Commission (no. WJ2019Q054).

\section{Author contributions}

D.W., L.H. designed this study; D.W. and X.Z. searched databases and collected full-text papers; L.H, and X.Z. extracted data; D.W. analyzed the data and wrote the manuscript; L.H. and X.Z. reviewed the manuscript. All of the authors have read and approved the final version of the manuscript.

\section{Competing interests}

The authors declare no competing interests.

\section{Additional information}

Correspondence and requests for materials should be addressed to L.H. or X.Z.

Reprints and permissions information is available at www.nature.com/reprints.

Publisher's note Springer Nature remains neutral with regard to jurisdictional claims in published maps and institutional affiliations.

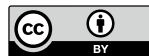

Open Access This article is licensed under a Creative Commons Attribution 4.0 International License, which permits use, sharing, adaptation, distribution and reproduction in any medium or format, as long as you give appropriate credit to the original author(s) and the source, provide a link to the Creative Commons licence, and indicate if changes were made. The images or other third party material in this article are included in the article's Creative Commons licence, unless indicated otherwise in a credit line to the material. If material is not included in the article's Creative Commons licence and your intended use is not permitted by statutory regulation or exceeds the permitted use, you will need to obtain permission directly from the copyright holder. To view a copy of this licence, visit http://creativecommons.org/licenses/by/4.0/.

(C) The Author(s) 2021 